\title{
Anaokullarında Görev Yapan Öğretmenlerin Okul Kültürü Algıları
}

\author{
DOI: 10.26466/opus.778544 \\ $*$ \\ Nejla Bayer Demirhan * - Zülfü Demirtaş ** \\ * Öğretmen, Milli Eğitim Bakanlığ1 \\ E-Posta: nejlaaa44@hotmail.com \\ ORCID: 0000-0002-8846-1746 \\ ** Prof. Dr., Furat Üniversitesi \\ E-Posta: zdemirtas@firat.edu.tr \\ ORCID: 0000-0002-1072-5772
}

\begin{abstract}
$\ddot{O} z$
Bu araştırmanın amacı anaokullarında çalışan okul öncesi öğretmenlerinin mevcut okul kültürü algılarını ortaya koymaktır. Bu araştırma betimsel tarama türünde bir çalışmadır. Araştırmanın çalışma grubunu 2019-2020 eğitim-öğretim yılında anaokullarında görev yapan öğretmenler oluşturmaktadır. Evren çok büyük olmadı̆̆ından örneklem alma yoluna gidilmeyerek evrenin tamamında yer alan öğretmenlerden veri toplanmıştır. Çalışma, Malatya il merkezi ve ilçelerindeki toplam 42 anaokulunda görev yapan 248 öğretmenle yürütülmüştür. Araştırmada veri toplama aracı olarak "Okul Kültürü Ölçeği" kullanılmıştır. Bu ölçek işbirlikçi liderlik, öğretmen işbirliği, mesleksel gelişme, amaç birliği ve meslektaş desteği boyutlarının altında yirmi yedi madde içermektedir. Verilerin analizinde; aritmetik ortalama, t-testi, ANOVA gibi sonuç, anlam ve çıkarım sağlayıcı istatistik teknikleri kullanılmıştır. Okul kültürü̈ ölçeğinin tüm alt boyutlardaki puan ortalamaları dikkate alınarak bir değerlendirme yapıldığında, öğretmenlerin okul kültürü algılarının üst düzeyde olduğu görülmektedir. Alt boyutlar noktasında puan ortalamalar dikkate alındiğında, amaç birliği boyutu en yüksek puan ortalamasına sahip iken, öğretmen işbirliği alt boyutunun da en düşük puan ortalamasına sahip olduğu görülmektedir.
\end{abstract}

Anahtar Kelimeler: okul kültürü, anaokulu, öğretmen 
ISSN:2528-9527

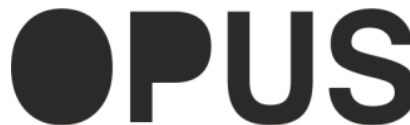

Uluslararası Toplum Araştırmaları Dergisi International Journal of Society Researches
E-ISSN : 2528-9535

YIl Year: 11

Cilt Volume: 17

Sayı Issue :35

Mart March 2021

Makalenin Geliș Tarihi Received Date: 10/08/2020

Makalenin Kabul Tarihi Accepted Date: 29/03/2021

\title{
School Culture Perceptions of Teachers Working in Kindergartens
}

\begin{abstract}
The aim of this research is to reveal the current school culture perceptions of preschool teachers working in kindergartens. This research is a descriptive study. The working group of the research consists of teachers working in all kindergartens that continue their activities in the city center and districts of Malatya in the 2019-2020 academic year. Since the universe is not very large, data was collected from the teachers in the entire universe by not taking a sample. The study was carried out with 248 teachers working in 42 kindergartens in Malatya city center and its districts. "School Culture Scale" developed by Demirtaş (2010b) was used as data collection tool in the study. This scale includes twenty-seven items under the dimensions of collaborative leadership, teacher cooperation, professional development, unity of purpose, and peer support. In the analysis of the data; Statistical techniques such as descriptive and t-test, ANOVA, such as arithmetic mean, providing result, meaning and inference were used. When an evaluation is made considering the mean scores of the school culture scale in all subdimensions, it is seen that teachers' perceptions of school culture are at the top level. When an evaluation is made by considering the mean scores at the point of sub-dimensions, it is seen that the highest mean value is in the unity of purpose, and the lowest average is in the teacher cooperation subdimension.
\end{abstract}

Keywords: school culture, kindergarten, teacher 


\section{Giriş}

Her toplumun kendine ait bir kültürü olduğu gibi nitelikli insan yetiştirmek amacıyla kurulan okulların da kendilerine özgü kültürleri vardır. Bazı okullar kendisini diğer okullardan farklı kılan, okul ortamına yeni katılanlara okul hakkında bilgi veren, okulda birlik ve beraberlik duygusu oluşturan, okulun nihai amacına ulaşmasına katkı sağlayıp başarılı olmasında etkili olan bir kültüre sahiptir. Kültür kavramı, bilgi birikimi ve eğitim; medeniyet ve uygarlık; güzel sanatlar ve üretim anlamında (Şişman, 1994, s.41) kullanılmaktadır. Buna karşılık okul kültürü kavramının; paylaşılan değerler, sayıltılar, normlar, inançlar, gelenekler, kutlamalar, mitler, etkileşimler, etkinlikler, ritüeller ve beklentiler (Demirtaş, 2010a, s. 5) anlamında kullanıldığına tanık olmaktayız. Okul kültürü, içinde bulunduğu toplumsal kültürün etkisine açı olduğundan, hem bu toplumsal kültüründen etkilenmekte hem de onu etkilemektedir (Köse ve diğerleri, 2010, s.25). Olumlu bir kültür, okulun gelişmesi için farklı ve yeni değişimlere olanak hazırlar. Okulun gelenek ve görenekleri, tarihi, okul çalışanlarının birikimleri ve aralarındaki etkileşim ve iletişimleri zaman içerisinde okulda özgün bir kültürün oluşmasına neden olur. Bu kültür; inanç, beklenti, norm, tutum, eğilim ve davranışlardan oluşmaktadır (Çelik, 2005, s. 32). Bunun sonucunda okulda hangi şeylerin değersiz görüldüğü, nelere önem verildiği, çalışanlar arasında nasıl hareket edileceği konusunda ortak bir tavır oluşmaktadır. Okulun asli görevi olan eğitim-öğretim sürecinde öğrenciden, öğretmenden ve diğer çalışanlardan nasıl davranmaları gerektiğini, nelere daha fazla önem verilmesi gerektiğini, nelerin okuldaki başarıyı daha fazla arttırdığını belirleyen etmen okul kültürüdür (Balc1, 2007, s.187).

Okulların içinde bulundukları toplumun amaçlarına ulaşması için çevresinden girdiler alarak eğitim-öğretim sürecinde işlediği ve oluşan her türlü değeri öğrencilere aktardığı görülmektedir (Balc1, 2005, s.161). Böylelikle okulun sahip olduğu mevcut kültür, çıktı şeklinde topluma sunulur. Sağlıklı bir okul kültürünün hakim olduğu okullarda örgütün değerleri ile öğretmenler ve okul yöneticilerinin uyumuna değer verilir (Fırat, 2010, s.75). Okulların kültürel yapısını ortaya koyan ve okulları birbirinden farklı kılan özelliklerle ilgili yapılan araştırmalarda, okul kültürünün fiziksel özelliklerden çok öğrenci, öğretmen ve yönetici iletişiminin yapısından kaynakland1ğı belirlenmiştir (Celep, 2002). Bunu sağlamak için hem okulda çalışma saat- 
leri içinde hem de okul dışında okul çalışanlarının iletişime geçebilecekleri, birbirlerini görebilecekleri ortamların sağlanmasına ihtiyaç duyulmaktadır. Bu bağlamda, olumsuz davranışların olumlu davranışlara dönüştürülmesiyle birlikte, olumlu davranışların takdir ve teşvik edilmesi beklenir ve çalışanların enerjilerini tüm okula yaymalarını sağlamak amacıyla kaynaştırıcı etkinliklere ihtiyaç duyulur (Işık, 2017, s.25). Olumlu ve işbirlikçi kültüre sahip bir okulda öğretmenler ve yöneticiler, okul yaşamını aile yaşamı gibi görürler. Öğretmenler kendi pozisyonlarına, yöneticileriyle ve meslektaşlarıyla olan ilişkilerine önem verir; öğrencilerine, işlerine ve birbirlerine karşı iyi duygular besler; öğrencileri kendi çabalarının merkezinde görürler (Demirtaş, 2010b, s.210). Olumlu bir okul kültürü öğretmenlerin başarısızlık, çatışma, okuldan soğuma gibi olumsuz duygulara maruz kalmasına engel teşkil edebilir (Fırat, 2007, s.50).

Güçlü bir kültüre sahip olan ve iyi yönetilen okullarda öğretmenler görevlerini severek yapar, öğrenciler okulda olmaktan zevk alır, okul dış çevre için cazibe haline dönüşür ve öğrencilerin akademik başarısı artar. Böyle bir okul ortamında, örgütsel bağlılık artar, okulun bütün paydaşları okulları ile gurur duyar. Bu durum okul kültürünün sürekliliği ve gücü üzerinde olumlu bir etki oluşturur (Önsal, 2012, s.35).

Kültür insanların ihtiyaçlarına göre yenilenen ve gelişen bir sistem olduğu için sürekli değişim halindedir. Okulda yapılan değişim girişimlerinin de kültüre uyumlu olmasına ihtiyaç duyulur. Aksi takdirde mevcut kültüre uymayan değişim girişimlerinin başarılı olması beklenmez. Okul yöneticileri açısından en zor işlerden biri mevcut kültürü değiştirmektir. Kültürel değişimi yöneticilerin bunu tek başına gerçekleştirmesi mümkün değildir. Bundan dolayı okul yöneticilerinin öncelikle okuldaki mevcut kültürü tanımaları ve okulda işlerin nasıl yürüdügünü bilmeleri gerekmektedir. Okul için değişim kaçınılmaz ise çalışanların buna inandırması ve karar verme sürecine dahil etmesi beklenir (Çelikten, 2006, s.60). Bu noktada önemli olan kültürün kontrollü ve planlı olarak değişiminin sağlanmasıdır (Kuyumcu, 2007, s.24). Okul kültürünün oluşturulmasında, sürdürülmesinde ve geliştirilmesinde yöneticilerin kültürel ve öğretimsel liderlik rolleri ön plana çlkmaktadır (Recepoğlu, 2014, s.220).

Son yıllarda eğitime ve okullara farklı görevler yüklenmiştir. Yeniden Kurmacilık akımının etkisiyle okullar aile kurumuna verilen önemin azaldığı, toplumsal değerlerin giderek zayıfladığı ve kültürel krizlerin yaşandığı 
günümüzde, kültürel değerlerin yeniden canlanmasını ve topluma yeniden yön verecek bireyler yetişmesini sağlayacak kurumlar olarak görülmeye başlanmıştır (Turhan, 2007, s. 44). Bu görevleri üstlenen okulların başarı sağlayabilmesi için olumlu ve güçlü bir okul kültürü oluşturmaları gerekmektedir.

Okuldaki mevcut kültür ile sürekli etkileşim halinde olan öğrencinin davranışsal, bilişsel ve duyuşsal değişikliklere uğraması kaçınılmazdır. Bu bağlamda okul kültürünün, öğrencinin öğrenmesi üzerinde etkili olması söz konusudur. Öğrencinin akademik başarısının temelini onun öğrenmesi oluşturur. Öğrencinin başarısını etkileyen ve eğitim-öğretim ortamından kaynaklanan faktörler okul kültüründen etkilenir. Okul kültürü öğrenci başarısına etki eden bazı faktörleri etkilemekte, bu faktörler ise öğrenci başarısını etkilemektedir (Demirtaş, 2010b, s. 211). Okul kültürü verimliliğin artmasına katkı sağlar (Atay, 2001, s. 181). Bazı okulların genel olarak öğrenci başarısına odaklanan olumlu bir kültüre sahip oldukları ancak öğretmen ve öğrencileri motive etmede zayıf kaldıkları; örneğin okul liderlerinin inançlar ve değerler hakkında konuşabildikleri ancak gelenek, tören, eylem ve ritüelleri takip etmedikleri görülmektedir (Jerald, 2006, s. 5). Okulda devamsızlık oranlarının fazla olması, okul kültürü ile yakından ilgili bir durumdur. Öğrenci okulu itici ya da çekici güç merkezi olarak algilayabilir. Öğrenciler, güçlü okul kültürünün hakim olduğu okullarda çevrede bulduklarından çok daha fazlasını okulda bulabilirler (Çelik, 2002, s. 144).

Okul kültürü; öğretmenlerin okulu sahiplenmesi, işlerini severek yapması, öğrencilerin akademik ve sosyal başarılarına olumlu katkılarda bulunması ve meslektaşları ile işbirliği içerisinde çalışmaları üzerinde etkilidir. Güçlü kültüre sahip bir okulun eğitsel amaçları gerçekleştirmede zayıf kültüre sahip bir okula göre daha fazla etkili olması beklenir. Okullarda hakim olan kültürün güçlü mü yoksa zayıf mı olduğunu anlamanın en etkili yolunun öğretmen algılarını ölçmekten geçtiğini söyleyebiliriz.

$\mathrm{Bu}$ araştırmanın temel amacı anaokullarında görev yapmakta olan öğretmenlerin okul kültürü algılarını ortaya çıarmaktır. Bu amaç doğrultusunda aşağıdaki sorulara yanıtlar aranmaktadır.

Anaokulu öğretmenlerinin okul kültürü algılarl;

- Hangi düzeydedir?

- Cinsiyete göre anlamlı farkl1lıklar göstermekte midir?

- Yaşa göre anlamlı farklılıklar göstermekte midir? 
- Kıdeme göre anlamlı farklılıklar göstermekte midir?

- Okuldaki hizmet süresine göre anlamlı farklılıklar göstermekte midir?

- Sendika üyesi olup olmama durumuna göre anlamlı farklılıklar göstermekte midir?

\section{Yöntem}

\section{Araştırmanın Modeli}

Araştırma anaokullarında görev yapmakta olan öğretmenlerin okul kültürüne ilişkin algılarının belirlenmesi, bu algıların cinsiyet, yaş, kıdem, okuldaki hizmet süresi ve sendika üyeliği değişkenlerine göre farklılaşıp farkl1laşmadığının tespit edilmesi amacıyla yapılan tarama türünde bir çalışmadir.

\section{Evren ve Örneklem}

Araştırmanın evrenini Malatya il ve ilçe milli eğitim müdürlüklerine bağlı 2019-2020 eğitim-öğretim yılında anaokullarında görev yapan öğretmenler oluşturmaktadır. Evren çok büyük olmadığından örneklem alma yoluna gidilmeyerek evrenin tamamında yer alan öğretmenlerden veri toplanmıştır. Çalışma kapsamında Malatya il merkezi ve ilçelerindeki tüm anaokullarına ulaşılmıştır. 42 anaokulunda görev yapan 248 öğretmenin tamamına ölçekler dağıtılmıştır ancak geri dönen 187 anketten sağlıklı doldurulmadı̆̆ 1 tespit edilen 3 anket değerlendirme dışı bırakılmıştır. Araştırmaya katılan öğretmenler, araştırma evreninin \%75'ini oluşturmaktadır. Bu bağlamda uygun şekilde doldurulan 184 anket değerlendirmeye alınmıştır. Tablo 1'de katılımcıların demografik özelliklerine ayrıntılı olarak yer verilmiştir.

Araştırmaya katılan öğretmenlerin demografik özelliklerinin verildiği Tablo 1'e göre, katılımcıların \% 91,8'i kadın öğretmenlerden oluşurken, \% 8,2 'si ise erkek öğretmenlerden oluşmaktadır. Yaş değişkenine göre, öğretmenlerin \% 23,9'unu 30 ve daha düşük yaşta, \% 62,5'ini 31-40 yaş arasında, $\% 13,6$ 's1 ise 41 yaş ve üzerindedir. Öğretmenlerin öğretmenlikteki hizmet süresi değişkenine göre dağılımına bakıldığında, \% 10,3'ünün 1-5 yıl arası, $\%$ 76,1'inin 6-15 yıl arası, \% 12'sinin 16-25 yıl arası ve \% 1,6'sinin 25 yıl ve üzeri hizmet süresine sahip olduğu görülmektedir. Herhangi bir sendikaya üye olup olmama durumu değişkenine göre öğretmenlerin dağılımı ince- 
lendiğinde, \%74,5' inin bir sendika üyesi olduğu, \%25,5'inin ise herhangi bir sendikaya üye olmadığı görülmektedir.

Tablo 1. Araştırmaya Katılan Öğretmenlerin Demografik Özellikleri

\begin{tabular}{|c|c|c|c|}
\hline Demografik Özellik & Gruplar & n & $\%$ \\
\hline \multirow{3}{*}{ Cinsiyet } & Kadın & 169 & 91,8 \\
\hline & Erkek & 15 & 8,2 \\
\hline & Toplam & 184 & 100,0 \\
\hline \multirow{4}{*}{ Yaş } & 30 yaş ve daha az & 44 & 23,9 \\
\hline & 31-40 yaş arası & 115 & 62,5 \\
\hline & 41 yaş ve üzeri & 25 & 13,6 \\
\hline & Toplam & 184 & 100,0 \\
\hline \multirow{5}{*}{$\begin{array}{l}\text { Öğretmenlikteki } \\
\text { Hizmet Süresi }\end{array}$} & $1-5 \mathrm{yll}$ & 19 & 10,3 \\
\hline & $6-15 \mathrm{yll}$ & 140 & 76,1 \\
\hline & $16-25$ yll & 22 & 12,0 \\
\hline & 25 yll ve üzeri & 3 & 1,6 \\
\hline & Toplam & 184 & 100,0 \\
\hline \multirow{4}{*}{$\begin{array}{l}\text { Çalıştı̆̆ı Okuldaki } \\
\text { Hizmet Süresi }\end{array}$} & A. $1-5 \mathrm{yll}$ & 124 & 67,4 \\
\hline & B. 6-15 y1l & 57 & 31,0 \\
\hline & C. $16-25$ yil & 3 & 1,6 \\
\hline & Toplam & 184 & 100,0 \\
\hline \multirow{3}{*}{ Sendika Üyelik Durumu } & Evet & 137 & 74,5 \\
\hline & Hayır & 47 & 25,5 \\
\hline & Toplam & 184 & 100,0 \\
\hline
\end{tabular}

\section{Veri Toplama Aracı}

Veri toplama aracı iki bölümden oluşmaktadır. Birinci bölümde, öğretmenlerin cinsiyet, yaş, öğretmenlikteki hizmet süresi, çalıştığı okuldaki hizmet süresi ve sendika üyelik durumunun yer aldığ 1 toplam beş değişkenden oluşan demografik bilgiler yer almaktadır. İkinci bölümde ise 27 maddeden oluşan Demirtaş'in (2010a) geliştirdiği “Okul Kültürü Ölçeği” yer almaktadir.

Demirtaş (2010a) geliştirdiği ölçeğin geçerlik ve güvenirlik analizlerini yapmıştır. Cronbach analizi sonucunda işbirlikçi liderlik için $\alpha=.89$, öğretmen işbirliği için $\alpha=.68$, mesleksel gelişme için $\alpha=.73$, amaç birliği için $\alpha=$ .72, mesleksel destek için $\alpha=.76$ olarak hesaplamıştır. Ölçeğin geneli itibariyle hesaplanan güvenirlik katsayısı ise $\alpha=.94$ olarak bulunmuştur. Okul Kültürü Ölçeği "asla katılmıyorum, katılmıyorum, orta düzeyde katılıyorum, katılıyorum, tamamen katılıyorum" seçeneklerinin yer aldığı beşli Likert tipinde bir ölçektir. Ölçekte katılımcıların puan ortalamalarının artması, 
öğretmenlerin okul kültürü algılarının olumlu yönde yüksek olması anlamina gelmektedir.

\section{Verilerin Analizi}

İlk olarak yanıtlanmış tüm ölçek formları, araştırmacılar tarafından tek tek incelenerek sağlıklı doldurulmamış üç adet ölçek formu analiz dışı tutulmuştur. Eksiksiz şekilde doldurulan toplam 184 ölçek formu araştırma için veri kaynağı olarak değerlendirilmeye alınmıştır.

Ölçekteki seçeneklerin sayısal puanlarının, betimsel değerlendirme ifadelerine dönüşümü Tablo 2'de verildiği şekilde yapılmıştır.

Tablo 2. Araştırma Ölçeğindeki Seçeneklerin Puanlara Göre Dağılımı

\begin{tabular}{clc}
\hline Derece & Seçenekler & Puan Aralıkları \\
\hline 5 & Tamamen Katılıyorum & $4.21-5.00$ \\
4 & Katıliyorum & $3.41-4.20$ \\
3 & Orta Düzeyde Katıliyorum & $2.61-3.40$ \\
2 & Katılmiyorum & $1.81-2.60$ \\
1 & Asla Katılmiyorum & $1.00-1.80$ \\
\hline
\end{tabular}

Okul Kültürü ölçeğinin toplam puanlarının normal dağılım gösterip göstermediğini belirlemek için yapılan histogram ve Q-Q plot analizleri aşağıda sunulmuştur. 

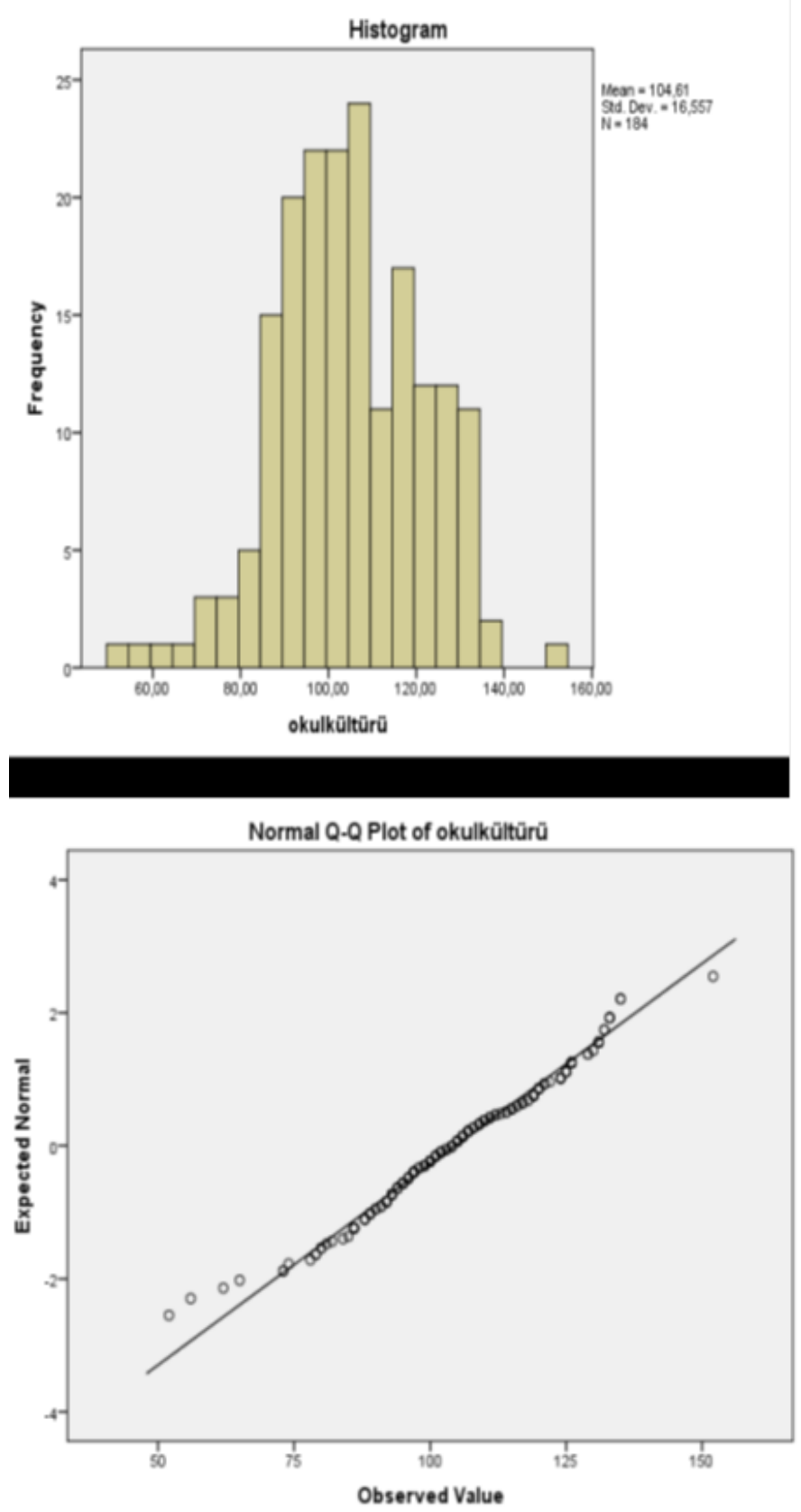
Okul kültürü ölçeğinin histogram ve $Q-Q$ plot grafikleri incelendiğinde ölçek toplam puanlarının normal dağılım gösterdiği görülmektedir.

\section{Bulgular}

Bu bölümde 2019-2020 eğitim öğretim yılı bahar döneminde Malatya merkez ve ilçelerindeki bütün anaokullarında çalışan okul öncesi öğretmenlerinin okul kültürü algılarına, bu konudaki görüşlerine ilişkin bulgu ve yorumlara yer verilmiştir.

Anaokulunda görev yapan okul öncesi öğretmenlerinin okul kültürü algılarına ilişkin bulgular, öğretmenlerin okul kültürü algılarının işbirlikçi liderlik, öğretmen işbirliği, mesleksel gelişim, amaç birliği, mesleksel destek ve okul kültürü algılarının toplamı düzeylerine ilişkin bulgular ve yorumlara yer verilmiştir.

Tablo 3. Okul Kültürü Ölçeği Toplam ve alt Toplamlarnnın İstatistik Değerleri

\begin{tabular}{lcccl}
\hline Alt Boyutlar & $\mathrm{N}$ & $\overline{\mathrm{X}}$ & $\mathrm{SS}$ & Aralık \\
\hline İşbirlikçi Liderlik & 184 & 3,78 & 0,72 & Katılıyorum \\
Öğretmen İşbirliği & 184 & 3,50 & 0,82 & Katıllyorum \\
Mesleksel Gelişim & 184 & 3,94 & 0,67 & Katıllyorum \\
\hline Amaç Birliği & 184 & 4,13 & 0,70 & Katıllyorum \\
Mesleksel Destek & 184 & 3,99 & 0,84 & Katıliyorum \\
Toplam değerlendirme & 184 & 3,86 & 0,75 & Katıllyorum \\
\hline
\end{tabular}

Tablo 3'teki puan ortalamaları dikkate alınarak bir değerlendirme yapıldığ 1 takdirde, okul kültürü alt boyutlarına ilişkin en yüksek ortalama değerin $(\odot=4,13 ;+0,70)$ ile amaç birliği alt boyutunda olduğu görülecektir. Amaç birliği alt boyutunu sırasiyla mesleksel destek $(\odot=3,99 ;+0,84)$, mesleksel gelişim $(\odot=3,94 ;+0,67)$, işbirlikçi liderlik $(\odot=3,78$; $+0,72)$ alt boyutları izlemektedir. En düşük ortalamanın ise $(\odot=3,50 ;+0,82)$ ile öğretmen işbirliği alt boyutunda olduğu görülmektedir. Tüm alt boyutlardaki puan ortalamalarına göre ise, öğretmenlerin okul kültürü algılarının, üst düzeyde olduğu söylenebilir.

Tablo 4. Okul Kültürü̈ Ölçeği Maddelerinin Tanılayıcı İstatistik Değerleri

\begin{tabular}{lcc}
\hline Maddeler & ○) & SS \\
\hline 1. Liderler öğretmenlerin düşüncelerine önem verirler. & 3,89 & .91 \\
\hline 2. Bu okuldaki liderler öğretmenlerin mesleksel kararlarına güvenirler. & 3,86 & .92 \\
\hline 3. Liderler iyi iş yapan öğretmenleri övmeye zaman ayırırlar. & 3,55 & 1,01 \\
\hline 4. Öğretmenler karar verme sürecine dâhil edilir. & 3,87 & .95 \\
\hline
\end{tabular}




\begin{tabular}{|c|c|c|}
\hline 5. Okulumuzdaki liderler öğretmelerin birlikte çalışmaları için kolaylık sağlarlar. & 3,95 & .83 \\
\hline 6. Öğretmenler okuldaki güncel konulardan haberdar edilir. & 4,13 & .87 \\
\hline 7. Politika oluşturma ya da karar verme sürecine katılımım ciddi olarak sağlanır. & 3,79 & .89 \\
\hline 8. Öğretmeler yeni düşünceler ve teknikler geliştirdikleri zaman ödüllendirilirler. & 3,09 & 1,15 \\
\hline 9. Liderler risk almayı ve öğretimde yeniliği destekler. & 3,65 & 1,02 \\
\hline 10. Yöneticiler öğretim ve planlamaya zaman ayırırlar. & 3,88 & .87 \\
\hline 11. Öğretmenler düşüncelerini paylaşmaya teşvik edilir. & 3,96 & .92 \\
\hline 12. Öğretmenler birlikte plan yapmaya fazla zaman ayırırlar. & 3,46 & .94 \\
\hline 13. Öğretmenler birbirinin öğretimini gözlemeye zaman ayırırlar. & 3,34 & 1,00 \\
\hline 14. Öğretmenler programları ve projeleri geliştirmek ve değerlendirmek için birlikte çalışırlar. & 3,69 & .92 \\
\hline $\begin{array}{l}\text { 15. Öğretmenler bilgiye ve sınıftaki öğretim kaynaklarına ulaşmak için profesyonel } \\
\text { bir şekilde internet kullanırlar }\end{array}$ & 3,98 & .86 \\
\hline $\begin{array}{l}\text { 16. Öğretmenler düzenli olarak seminerlerden, konferanslardan ve meslektaşlarından } \\
\text { düşünceler araştırırlar. }\end{array}$ & 3,66 & .91 \\
\hline 17. Öğretmenler mesleksel gelişmeye değer verirler. & 4,01 & .78 \\
\hline 18. Öğretmenler öğretim süreci ile ilgili temel bilgilerini güncelleştirirler. & 4,01 & .75 \\
\hline 19. Öğretmenler okul geliştirmeye değer verirler. & 4,05 & .78 \\
\hline 20. Öğretmenler okulun misyonunun desteklerler. & 4,15 & .73 \\
\hline 21. Öğretmenler okulun misyonunu anlarlar. & 4,13 & .77 \\
\hline 22. Okul misyonu ifadesi toplumun değerlerini yansitır. & 4,13 & .76 \\
\hline 23. Öğretim performansı okulun misyonunu yansıtır. & 4,12 & .79 \\
\hline 24. Öğretmenler birbirlerine güvenirler. & 3,88 & .90 \\
\hline 25. Öğretmenler bir problem olduğu zaman yardım etmeye gönüllüdürler. & 4,03 & .94 \\
\hline 26. Öğretmenler birbirlerinin düşüncelerine değer verirler. & 4,04 & .89 \\
\hline 27. Öğretmenler grup içerisinde işbirlikçi bir şekilde çalışırlar. & 4,03 & .90 \\
\hline
\end{tabular}

Okul kültürü ölçeğinin 1-11. maddeleri işbirlikçi liderlik alt boyutuna aittir. Bu alt boyuttaki en yüksek ortalama $(\circledast=4,13 ;+0,87)$ ile 6 . maddeye (Öğretmenler okuldaki güncel konulardan haberdar edilir) aittir. Bu puan ortalaması öğretmenlerin okuldaki güncel olaylar hakkında bilgi sahibi olduklarını göstermektedir. En düşük ortalama ise, $(\Theta=3,09 ;+1,15)$ ile 8 . maddeye (Öğretmeler yeni düşünceler ve teknikler geliştirdikleri zaman ödüllendirilirler) aittir. Bu ortalama öğretmenlerin ödüllendirme noktasında pek de memnun olmadıklarını göstermektedir. Öğretmenlerin diğer maddelere verdikleri cevapların, işbirlikçi liderlik alt boyutu ortalamasının genel anlamda üzerinde olduğu görülmektedir. Bu sonuç, öğretmenlerin birbirleriyle iletişim ve etkileşim halinde oldukları, birbirlerine yardım ettikleri ve işbirliği yaptıkları şeklinde açıklanabilir.

Okul kültürü ölçeğinin 12-13 ve 14. maddeleri öğretmen işbirliği alt boyutuna aittir. Bu alt boyuttaki en yüksek ortalama $(\odot=3,69 ;+0,92)$ ile 14 . maddeye (Öğretmenler programları ve projeleri geliştirmek ve değerlen- 
dirmek için birlikte çalışırlar) aittir. 14. maddeyi $(\Theta=3,46 ;+0,94)$ ortalama ile 12. madde (Öğretmenler birlikte plan yapmaya fazla zaman ayırırlar) izlemektedir. En düşük ortalama ise, $(\odot=3,34 ;+1,00)$ ile 13 . maddeye (Öğretmeler yeni düşünceler ve teknikler geliştirdikleri zaman ödüllendirilirler) aittir. Okul kültürü ölçeğinin tüm alt boyutları arasında en düşük puan ortalamasının öğretmen işbirliği alt boyutunda olduğu görülmektedir. Bu sonuç öğretmenlerin birlikte plan ve program hazırlama, proje geliştirme, birbirlerinin eğitim-öğretim etkinliklerini gözlemleme ve birlikte değerlendirme yapma noktasında yeterince işbirliği yapmadıkları şeklinde yorumlanabilir.

Okul kültürü ölçeğinin 15-19. maddeleri mesleksel gelişim alt boyutuna aittir. Bu alt boyuttaki en yüksek ortalama $(\odot=4,05 ;+0,78)$ ile 19 . maddeye (Öğretmenler okul geliştirmeye değer verirler) aittir. 19. maddeyi (๑)=4,01; $+0,78$ ) ortalama ile 17. madde (Öğretmenler mesleksel gelişmeye değer verirler) ve 18. madde (Öğretmenler öğretim süreci ile ilgili temel bilgilerini güncelleştirirler) izlemektedir. 15. madde ise (Öğretmenler bilgiye ve sinıftaki öğretim kaynaklarına ulaşmak için profesyonel bir şekilde internet kullanırlar) $(\odot=3,98 ;+0,86)$ ortalamaya sahiptir. En düşük ortalama ise, $(\circledast=3,66$; $+0,91$ ) ile 16. maddeye (Öğretmenler düzenli olarak seminerlerden, konferanslardan ve meslektaşlarından düşünceler araştırırlar) aittir. Alt boyutlar temelinde puan ortalamalarına bakıldığı zaman, mesleksel gelişim alt boyutu $(\odot=3,94 ;+0,67)$ ortalama ile üçüncü sırada yer almaktadır. Mesleksel gelişim puan ortalamalarının yüksekliği dikkate alındığı zaman, öğretmenlerin mesleki gelişmeye önem verdikleri, okulu geliştirmek için çaba gösterdikleri, bilgilerini güncel tutmak için çeşitli faaliyetlerde bulundukları söylenebilir.

Okul kültürü ölçeğinin 20-23. maddeleri amaç birliği alt boyutuna aittir. Bu alt boyuttaki en yüksek ortalama $(\Theta=4,15 ;+0,73)$ ile 20 . maddeye (Öğretmenler okulun misyonunun desteklerler) aittir. 21. madde (Öğretmenler okulun misyonunu anlarlar) ve 22. madde (Okul misyonu ifadesi toplumun değerlerini yansitır) $(\Theta=4,13 ;+0,76)$ ortalamaya sahiptir. En düşük ortalama ise $(\odot=4,12 ;+0,79)$ ile 23 . maddeye (Öğretim performansı okulun misyonunu yansitır) aittir. Bu alt boyuttaki tüm maddelerin puan ortalamasının birbirine çok yakın olduğu görülmektedir. Okul kültürü ölçeğinin alt boyutlar temelinde puan ortalamaları incelediğinde en yüksek ortalamanın (๑)=4,13; $+0,70$ ) ile amaç birliği alt boyutunda olduğu görülmektedir. Bu sonuç, araştırmaya katılan öğretmenlerin okulun misyonunu anladıklarını, destekle- 
diklerini ve okulun misyonunun toplumun değerlerini yansittığ1 şeklinde yorumlanabilir.

Okul kültürü ölçeğinin 24-27. maddeleri mesleksel destek alt boyutuna aittir. Bu alt boyuttaki en yüksek ortalama $(\Theta=4,04 ;+0,89)$ ile 26 . maddeye (Öğretmenler birbirlerinin düşüncelerine değer verirler) aittir. 25. madde (Öğretmenler bir problem olduğu zaman yardım etmeye gönüllüdürler) ve 27. madde (Öğretmenler grup içerisinde işbirlikçi bir şekilde çalışırlar) $(\odot=4,03 ;+0,90)$ ortalamaya sahiptir. En düşük ortalama ise $(\odot=3,88 ;+0,90) 24$. maddeye (Öğretmenler birbirlerine güvenirler) aittir. Okul kültürü ölçeğinin alt boyutlar temelinde puan ortalamaları incelediğinde mesleksel destek alt boyutunun $(\odot=3,99 ;+0,84)$ ortalama ile en yüksek puan ortalamasina sahip ikinci alt boyut olduğu görülecektir. Bu sonuç, öğretmenlerin birbirlerine güvendikleri, yardım ettikleri, birbirlerinin düşüncelerine önem verdikleri ve işbirlikçi bir şekilde çalıştıkları şeklinde yorumlanabilir.

\section{Cinsiyet Değişkeni Açısından Öğretmenlerin Okul Kültürü̈ Algılarn}

Cinsiyet değişkeni açısından, anaokullarında görev yapan öğretmenlerin okul kültürü algıları arasında anlamlı farklılaşma olup olmadığını sınamak amacıyla, iki grubun okul kültürü alt boyut ortalamaları arasındaki farklılığı belirlemek üzere ilişkisiz örneklemler için $t$ testi yapılmış ve bulguları Tablo 5 'de verilmiştir.

Tablo 5. Cinsiyet Değişkeni Açısından Okul Kültürü Ölçeği Alt Boyutlarna İlişkin İlişkisiz Örneklemler İçin t Testi Sonuçlarn

\begin{tabular}{|c|c|c|c|c|c|c|c|}
\hline Boyutlar & Gruplar & $\mathrm{N}$ & $\bar{X}$ & SS & SD & $\mathrm{t}$ & $\mathrm{p}$ \\
\hline \multirow{3}{*}{ İşbirlikçi Liderlik } & A) Kadın & 169 & 3,75 & 0,73 & & & \\
\hline & B) Erkek & 15 & 4,15 & 0,48 & 182 & $-2,076$ &, $039^{*}$ \\
\hline & Toplam & 184 & & & & & \\
\hline \multirow{3}{*}{ Öğretmen İşbirliği } & A) Kadın & 169 & 3,48 & 0,83 & & & \\
\hline & B) Erkek & 15 & 3,73 & 0,65 & 182 & $-1,137$ & 257 \\
\hline & Toplam & 184 & & & & & \\
\hline \multirow{3}{*}{ Mesleksel Gelişim } & A) Kadın & 169 & 3,94 & 0,69 & & & \\
\hline & B) Erkek & 15 & 4,00 & 0,42 & 182 &,- 312 & ,756 \\
\hline & Toplam & 184 & & & & & \\
\hline \multirow{3}{*}{ Amaç Birliği } & A) Kadın & 169 & 4,12 & 0,71 & & & \\
\hline & B) Erkek & 15 & 4,26 & 0,54 & 182 &,- 752 & ,453 \\
\hline & Toplam & 184 & & & & & \\
\hline \multirow{3}{*}{ Mesleksel Destek } & A) Kadın & 169 & 3,96 & 0,85 & & & \\
\hline & B) Erkek & 15 & 4,40 & 0,63 & 182 & $-1,934$ & ,055 \\
\hline & Toplam & 184 & & & & & \\
\hline
\end{tabular}

${ }^{*} \mathrm{p}<.05$ 
Okul kültürü ölçeğinin cinsiyet değişkenine göre farklılık gösterip göstermediğini belirlemek için yapılan ilişkisiz örneklemler için $t$ testine göre, işbirlikçi liderlik boyutu [ $\left.\mathrm{t}_{184}=-2,076, \mathrm{p}<.05\right]$, öğretmen işbirliği boyutu [ $\mathrm{t}_{184}=-$ 1,137, p>.05], mesleksel gelişim boyutu [t184= -,312, p>.05], amaç birliği boyutu [ $\left.\mathrm{t}_{184}=-, 752, \mathrm{p}>.05\right]$ ve mesleksel destek boyutu [t $\left.\mathrm{t}_{184}=1,934, \mathrm{p}>.05\right]$ hesaplanmıştır. Kadın öğretmenlerin puan ortalamaları ile erkek öğretmenlerin puan ortalamaları arasında işbirlikçi liderlik boyutu dışında anlamlı bir farklılık görülmemiştir. İşbirlikçi liderlik boyutunda erkek öğretmenlerin lehine anlamlı bir farklılık olduğu görülmektedir. Bu bulguya göre erkek öğretmenler, okul yöneticilerinin öğretmenlerin aralarında işbirliği yapmalarına ve birbirleri ile etkileşimde bulunmalarına yardım eden davranışlar sergilediği yönündeki yargılara daha fazla katılmaktadırlar. Dikkat çeken bir diğer nokta ise, tüm alt boyutlarda erkek öğretmenlerin puan ortalamalarının kadın öğretmenlerden daha yüksek olduğudur. Bu sonuç erkek öğretmenlerin okul kültürü algılarının kadın öğretmenlerin okul kültürü alg1larından daha yüksek olduğu şeklinde açıklanabilir.

\section{Yaş Değişkeni Açısından Öğretmenlerin Okul Kültürü̈ Algıları}

Yaş değişkeni açısından, anaokullarında görev yapan öğretmenlerin okul kültürü algıları arasında anlamlı farklılaşma olup olmadığını sınamak amacıyla, üç grubun okul kültürü alt boyut ortalamaları arasındaki farklılığı belirlemek üzere Tek Yönlü Varyans Analizi Testi yapılmış ve sonuçları Tablo 6' da verilmiştir.

Tablo 6. Yaş Değişkeni Açısından Okul Kültürü̈ Ölçeği Alt Boyutlarına İlişkin Tek Yönlü Varyans Analizi Sonuçlan

\begin{tabular}{|c|c|c|c|c|c|c|c|c|}
\hline Boyutlar & Gruplar & $\mathrm{N}$ & $\overline{\mathrm{X}}$ & SS & $\mathrm{SD}$ & $\mathrm{F}$ & $\mathrm{P}$ & Fark \\
\hline & A) 30 yaş ve daha az & 44 & 3,66 & 0,70 & & & & \multirow{4}{*}{--} \\
\hline \multirow{3}{*}{$\begin{array}{l}\text { İşbirlikçi } \\
\text { Liderlik }\end{array}$} & B) $31-40$ yaş & 115 & 3,78 & 0,72 & $2-181$ & 2,059 & 131 & \\
\hline & C) 41 yaş ve üzeri & 25 & 4,02 & 0,72 & & & & \\
\hline & Toplam & 184 & & & & & & \\
\hline \multirow{4}{*}{$\begin{array}{l}\text { Ö̈̆retmen } \\
\text { İşbirliği }\end{array}$} & A) 30 yaş ve daha az & 44 & 3,43 & 0,91 & & & & \multirow{4}{*}{--} \\
\hline & B) $31-40$ yaş & 115 & 3,51 & 0,76 & $2-181$ & ,168 & ,846 & \\
\hline & C) 41 yaş ve üzeri & 25 & 3,53 & 0,93 & & & & \\
\hline & Toplam & 184 & & & & & & \\
\hline \multirow{4}{*}{$\begin{array}{l}\text { Mesleksel } \\
\text { Gelişim }\end{array}$} & A) 30 yaş ve daha az & 44 & 3,80 & 0,70 & & & & \multirow{4}{*}{--} \\
\hline & B) $31-40$ yaş & 115 & 3,99 & 0,63 & $2-181$ & 1,392 & 251 & \\
\hline & C) 41 yaş ve üzeri & 25 & 3,99 & 0,78 & & & & \\
\hline & Toplam & 184 & & & & & & \\
\hline
\end{tabular}




\begin{tabular}{|c|c|c|c|c|c|c|c|c|}
\hline \multirow{4}{*}{$\begin{array}{l}\text { Amaç } \\
\text { Birliği }\end{array}$} & A) 30 yaş ve daha az & 44 & 3,98 & 0,78 & & & & \\
\hline & B) $31-40$ yaş & 115 & 4,17 & 0,68 & $2-181$ & 1,347 & 263 & \\
\hline & C) 41 yaş ve üzeri & 25 & 4,23 & 0,59 & & & & \\
\hline & Toplam & 184 & & & & & & \\
\hline \multirow{4}{*}{$\begin{array}{l}\text { Mesleksel } \\
\text { Destek }\end{array}$} & A) 30 yaş ve daha az & 44 & 3,88 & 0,92 & & & & \multirow{4}{*}{-} \\
\hline & B) $31-40$ yaş & 115 & 4,05 & 0,78 & 2-181 & ,718 & 489 & \\
\hline & C) 41 yaş ve üzeri & 25 & 3,95 & 0,97 & & & & \\
\hline & Toplam & 184 & & & & & & \\
\hline
\end{tabular}

Üç farklı yaş kategorisine göre gruplandırılmış öğretmenlerin yaşlarına göre okul kültürü ölçeği alt boyutlarında aralarında anlamlı bir farkın olup olmadığına bakmak için Tek Yönlü Varyans Analizi Testi yapıldı. Yapılan Tek Yönlü Varyans Analizi testinde işbirlikçi liderlik alt boyutu [F-181= 2,059, $\mathrm{p}>$.05], öğretmen işbirliği alt boyutu [ $\left.\mathrm{F}_{2-181}=, 168, \mathrm{p}>.05\right]$, mesleksel gelişim alt boyutu [ $\left.\mathrm{F}_{2-181}=1,392, \mathrm{p}>.05\right]$, amaç birliği alt boyutu [ $\left.\mathrm{F}_{2-181}=1,347, \mathrm{p}>.05\right]$ ve mesleksel destek alt boyutu $\left[\mathrm{F}_{2-181}=, 718, \mathrm{p}>\right.$.05] olarak bulundu. Yaş değişkenine göre öğretmenlerin okul kültürü algıları arasında anlamlı bir farkın olmadığı görüldü. Ancak mesleksel destek alt boyutu hariç, diğer alt grupların tamamında 41 ve üzeri yaşa sahip olan öğretmenlerin puan ortalamalarının, diğer gruplardaki öğretmenlerin puan ortalamalarından yüksek olduğu görülmektedir. Mesleksel destek alt boyutunda ise, 31-40 arası yaşa sahip olan öğretmenlerin puan ortalamaları, diğer gruplardaki öğretmenlerin ortalamalarından yüksektir.

\section{Öğretmenlikteki Hizmet Süresi Değişkeni Açısından Öğretmenlerin Okul Kültürü Algılarn}

Farklı dört mesleki kıdeme göre gruplandırılan öğretmenlerin, okul kültürü algılarında hizmet süresi değişkenine göre aralarında anlamlı fark olup olmadığını belirlemek için, mesleki kıdemlerine göre oluşturulan grupların görüşlerinin ortalamaları ilişkisiz örneklemler için tek yönlü varyans analizi ile karşılaştırılmıştır. 
Tablo 7. Öğretmenlikteki Hizmet Süresi Değişkeni Açısından Okul Kültürü Ölçeği Alt Boyutlarnna İlişkin Tek Yönlü Varyans Analizi Sonuçlan

\begin{tabular}{|c|c|c|c|c|c|c|c|c|}
\hline Boyutlar & Gruplar & $\mathrm{N}$ & $\bar{X}$ & SS & $\mathrm{Sd}$ & $\mathrm{F}$ & $\mathrm{P}$ & Fark \\
\hline İşbirlikçi & A) $1-5$ yil & 19 & 3,63 & 0,80 & & & & --- \\
\hline \multirow[t]{4}{*}{ Liderlik } & B) 6-15 yıl & 140 & 3,85 & 0,70 & & & & \\
\hline & C) $16-25$ yıl & 22 & 3,45 & 0,66 & $3-180$ & 2,642 & 051 & \\
\hline & D) 25 yıl ve üzeri & 3 & 4,18 & 1,26 & & & & \\
\hline & Toplam & 184 & & & & & & \\
\hline Öğretmen & A) $1-5 \mathrm{yll}$ & 19 & 3,21 & 0,78 & & & & \\
\hline \multirow[t]{4}{*}{ İşbirliği } & B) 6-15 yıl & 140 & 3,58 & 0,82 & & & & \\
\hline & C) $16-25$ yıl & 22 & 3,22 & 0,75 & $3-180$ & 2,104 & 101 & -- \\
\hline & D) 25 yıl ve üzeri & 3 & 3,55 & 1,07 & & & & \\
\hline & Toplam & 184 & & & & & & \\
\hline Mesleksel & A) $1-5 \mathrm{yll}$ & 19 & 3,70 & 0,78 & & & & \\
\hline \multirow[t]{4}{*}{ Gelişim } & B) 6-15 yıl & 140 & 4,04 & 0,60 & & & & \\
\hline & C) $16-25$ yil & 22 & 3,46 & 0,75 & $3-180$ & 6,603 &, $000^{*}$ & $\mathrm{~B}-\mathrm{C}$ \\
\hline & D) 25 yıl ve üzeri & 3 & 4,40 & 1,03 & & & & \\
\hline & Toplam & 184 & & & & & & \\
\hline \multirow[t]{5}{*}{ Amaç Birliği } & A) $1-5$ yll & 19 & 4,10 & 0,71 & & & & \\
\hline & B) $6-15 \mathrm{yll}$ & 140 & 4,21 & 0,64 & & & & \\
\hline & C) $16-25$ yıl & 22 & 3,64 & 0,85 & $3-180$ & 4,396 &, $005^{*}$ & $\mathrm{~B}-\mathrm{C}$ \\
\hline & D) 25 yıl ve üzeri & 3 & 4,25 & 0,66 & & & & \\
\hline & Toplam & 184 & & & & & & \\
\hline Mesleksel & A) $1-5$ yıl & 19 & 3,85 & 0,77 & & & & \\
\hline \multirow[t]{4}{*}{ Destek } & B) 6-15 yıl & 140 & 4,09 & 0,82 & & & & \\
\hline & C) $16-25$ yıl & 22 & 3,51 & 0,86 & $3-180$ & 3,342 &, $021^{*}$ & $\mathrm{~B}-\mathrm{C}$ \\
\hline & D) 25 yıl ve üzeri & 3 & 4,16 & 1,23 & & & & \\
\hline & Toplam & 184 & & & & & & \\
\hline
\end{tabular}

${ }^{*} \mathrm{p}<.05$

Dört farklı mesleki kıdeme göre gruplandırılmış öğretmenlerin kıdemlerine göre okul kültürü ölçeği alt boyutlarında aralarında anlamlı bir farkın olup olmadığına bakmak için Tek Yönlü Varyans Analizi testi yapıldı. Yapılan Tek Yönlü Varyans Analizi testinde işbirlikçi liderlik alt boyutu [F-180=2,642, p>.05], öğretmen işbirliği alt boyutu [F3-180= 2,104, p>.05], mesleksel gelişim alt boyutu [F3-180=6,603, p<.05], amaç birliği alt boyutu $\left[\mathrm{F}_{3-180}=4,396, \mathrm{p}<.05\right]$ ve mesleksel destek alt boyutu [ $\mathrm{F}_{3-180}=3,342$, p<.05] olarak bulundu. Öğretmenlikteki hizmet süresi değişkenine göre öğretmenlerin okul kültürü algılarında mesleksel gelişim, amaç birliği ve mesleksel destek alt boyutlarında anlamlı farklar olduğu görüldü. Bu anlamlı farkın hangi gruplar arasında olduğunu belirlemek için Post Hoc testlerinden Scheffe testi ile analize devam edildi. Scheffe testi analizine göre anlamlı farkın 6-15 yıl hizmet süresine sahip öğretmenler ile 16-25 yıl hizmet süresine sahip öğretmenler arasında olduğu görüldü. Scheffe testi analizine göre 6-15 yıl hizmet süresine sahip 
öğretmenlerin mesleki gelişim, amaç birliği ve mesleksel destek algılarının 16-25 yıl hizmet süresine sahip öğretmenlerden daha yüksek olduğu görülmektedir. Ayrıca dikkat çeken bulgulardan biri de 25 yıl ve üzeri kıdeme sahip öğretmenlerin puan ortalamalarının, öğretmen işbirliği alt boyutu hariç diğer tüm alt boyutlarda diğer gruplardaki öğretmenlerin puan ortalamalarından yüksek olduğudur. Öğretmen işbirliği alt boyutunda ise 6-15 yıl kıdeme sahip öğretmenlerin puan ortalamaları diğer grupların puan ortalamalarından yüksektir.

\section{Çalıştığı Okuldaki Hizmet Süresi Değişkeni Açısından Öğretmenlerin Okul Kültürü Algıları}

Çalıştığı okuldaki hizmet süresine göre farklı üç gruba ayrılan öğretmenlerin, okul kültürü ölçeğine göre aralarında anlamlı fark olup olmadığını belirlemek için, çalıştıkları okuldaki hizmet sürelerine göre oluşturulan grupların görüşlerinin ortalamaları ilişkisiz örneklemler için tek yönlü varyans analizi ile karşılaştırılmıştır.

Tablo 8. Çalıştığı Okuldaki Hizmet Süresi Değişkeni Açısından Okul Kültürü Ölçeği Alt Boyutlarnna İlişkin Tek Yönlï Varyans Analizi Sonuçları

\begin{tabular}{|c|c|c|c|c|c|c|c|c|}
\hline Boyutlar & Gruplar & $\mathrm{N}$ & $\overline{\mathrm{X}}$ & SS & $\mathrm{Sd}$ & $\mathrm{F}$ & $\mathrm{P}$ & Fark \\
\hline İşbirlikçi & A) $1-5 \mathrm{yll}$ & 124 & 3,85 & 0,73 & & & & \multirow{4}{*}{--} \\
\hline \multirow[t]{3}{*}{ Liderlik } & B) 6-15 yıl & 57 & 3,64 & 0,67 & & & & \\
\hline & C) $16-25 \mathrm{yll}$ & 3 & 3,63 & 1,00 & $2-181$ & 1,825 & 164 & \\
\hline & Toplam & 184 & & & & & & \\
\hline \multirow{4}{*}{$\begin{array}{l}\text { Öğretmen } \\
\text { İşbirliği }\end{array}$} & A) $1-5 \mathrm{yll}$ & 124 & 3,42 & 0,85 & & & & \multirow{4}{*}{--} \\
\hline & B) $6-15 \mathrm{yll}$ & 140 & 3,68 & 0,69 & & & & \\
\hline & C) $16-25 \mathrm{y} 1 \mathrm{l}$ & 22 & 3,22 & 1,57 & $2-181$ & 2,139 & 121 & \\
\hline & Toplam & 184 & & & & & & \\
\hline Mesleksel & A) $1-5 \mathrm{yll}$ & 124 & 3,93 & 0,66 & & & & \multirow{4}{*}{--} \\
\hline \multirow[t]{3}{*}{ Gelişim } & B) $6-15 \mathrm{yll}$ & 140 & 3,97 & 0,68 & & & & \\
\hline & C) $16-25 \mathrm{y} 1 \mathrm{l}$ & 22 & 3,86 & 1,02 & $2-181$ & ,084 & ,919 & \\
\hline & Toplam & 184 & & & & & & \\
\hline \multirow{4}{*}{$\begin{array}{l}\text { Amaç } \\
\text { birliği }\end{array}$} & A) $1-5$ yil & 124 & 4,15 & 0,67 & & & & \multirow{4}{*}{--} \\
\hline & B) $6-15 \mathrm{y} 1 \mathrm{l}$ & 140 & 4,08 & 0,76 & & & & \\
\hline & C) $16-25 \mathrm{y} 1 \mathrm{l}$ & 22 & 4,41 & 0,52 & $2-181$ & ,435 & 648 & \\
\hline & Toplam & 184 & & & & & & \\
\hline Mesleksel & A) $1-5$ yll & 19 & 3,97 & 0,86 & & & & \multirow{4}{*}{--} \\
\hline \multirow[t]{3}{*}{ Destek } & B) 6-15 yıl & 140 & 4,03 & 0,79 & & & & \\
\hline & C) $16-25$ yil & 22 & 4,25 & 1,08 & $2-181$ & ,210 &, 811 & \\
\hline & Toplam & 184 & & & & & & \\
\hline
\end{tabular}


Çalıştı̆̆ı okuldaki hizmet sürelerine göre üç farklı şekilde gruplandırılmış öğretmenlerin okul kültürü ölçeği alt boyutlarında aralarında anlamlı bir farkın olup olmadığına bakmak için Tek Yönlü Varyans Analizi testi yapıldı. Yapılan Tek Yönlü Varyans Analizi testinde işbirlikçi liderlik alt boyutu $\left[\mathrm{F}_{2-181}=1,825, \mathrm{p}>.05\right]$, öğretmen işbirliği alt boyutu $\left[\mathrm{F}_{2-181}==2,139\right.$, $\mathrm{p}>$.05], mesleksel gelişim alt boyutu [ $\mathrm{F}_{2-181}=084$, $\left.\mathrm{p}>.05\right]$, amaç birliği alt boyutu $\left[\mathrm{F}_{2-181}==, 435, \mathrm{p}>.05\right]$ ve mesleksel destek alt boyutu $\left[\mathrm{F}_{2-181}==, 210, \mathrm{p}>.05\right]$ olarak bulundu. Çalıştığı okuldaki hizmet süresi değişkenine göre öğretmenlerin okul kültürü algıları arasında anlamlı bir farkın olmadığı görüldü.

\section{Sendikaya Üyelik Durumu Değişkeni Açısından Öğretmenlerin Okul Kültü- rü Algilarn}

Sendikaya üyelik durumu değişkeni açısından, anaokullarında görev yapan öğretmenlerin okul kültürü algıları arasında anlamlı farklılaşma olup olmadığını sınamak amacıyla, iki grubun okul kültürü alt boyut ortalamaları arasındaki farklılığı belirlemek üzere ilişkisiz örneklemler için $t$ testi yapılmış ve sonuçları Tablo 9' de verilmiştir.

Tablo 9. Sendikaya Üyelik Durumu Değisşkeni Açısından Okul Kültürü Ölçeği Alt Boyutlarnna İlişkin İlişkisiz Örneklemler İçin t Testi Sonuçları

\begin{tabular}{|c|c|c|c|c|c|c|c|}
\hline Boyutlar & Gruplar & $\mathrm{N}$ & $\bar{X}$ & SS & Sd & $\mathrm{t}$ & $\mathrm{p}$ \\
\hline \multirow{3}{*}{ İşbirlikçi Liderlik } & A) Üye & 137 & 3,80 & 0,72 & & & \\
\hline & B) Üye Değil & 47 & 3,75 & 0,73 & 182 &, 374 & ,709 \\
\hline & Toplam & 184 & & & & & \\
\hline \multirow{3}{*}{ Öğretmen İşbirliği } & A) Üye & 137 & 3,49 & 0,81 & & & \\
\hline & B) Üye Değil & 47 & 3,51 & 0,86 & 182 &,- 153 & ,878 \\
\hline & Toplam & 184 & & & & & \\
\hline \multirow{3}{*}{ Mesleksel Gelişim } & A) Üye & 137 & 3,95 & 0,65 & & & \\
\hline & B) Üye Değil & 47 & 3,93 & 0,74 & 182 & ,187 &, 852 \\
\hline & Toplam & 184 & & & & & \\
\hline \multirow{3}{*}{ Amaç Birliği } & A) Üye & 137 & 4,15 & 0,67 & & & \\
\hline & B) Üye Değil & 47 & 4,06 & 0,76 & & & \\
\hline & Toplam & 184 & & & 182 &, 754 &, 452 \\
\hline \multirow{3}{*}{ Mesleksel Destek } & A) Üye & 137 & 4,04 & 0,82 & & & \\
\hline & B) Üye Değil & 47 & 3,86 & 0,89 & 182 & 1,290 & 199 \\
\hline & Toplam & 184 & & & & & \\
\hline
\end{tabular}

Herhangi bir sendikaya üyelik durumu değişkeni açısından yapılan ilişkisiz örneklemler için $\mathrm{t}$ testine göre, işbirlikçi liderlik boyutu [ $\mathrm{t}_{184}=, 374$, $\mathrm{p}>0.05]$, öğretmen işbirliği boyutu [t184=-,153, p>0.05], mesleksel gelişim bo- 
yutu [ $\left.\mathrm{t}_{184}=, 187, \mathrm{p}>0.05\right]$, amaç birliği boyutu [ $\left.\mathrm{t}_{184}=, 754, \mathrm{p}>0.05\right]$ ve mesleksel destek boyutu [ $\left.\mathrm{t}_{184}=1,290, \mathrm{p}>0.05\right]$ bulunmuştur. Okul kültürü ölçeğinin tüm alt boyutlarında herhangi bir sendikaya üye olan öğretmenlerin puan ortalamaları ile herhangi bir sendikaya üye olmayan öğretmenlerin puan ortalamaları arasında anlamlı bir farklılık görülmemiştir. Aynı zamanda öğretmen işbirliği alt boyutu dışında tüm alt boyutlarda sendikaya üye olan öğretmenlerin puan ortalamalarının, sendika üyesi olmayan öğretmenlerin puan ortalamalarından yüksek olduğu görülmektedir.

\section{Sonuçlar ve Tartışma}

Okul kültürü ölçeğinin tüm alt boyutlardaki puan ortalamaları dikkate al1narak bir değerlendirme yapıldığında, öğretmenlerin okul kültürü algilarının üst düzeyde olduğu görülmektedir. Şahin (2017), Fırat (2007) ve Taner'in (2008) yaptığı çalışmalarda da buna benzer sonuçlar elde etmiştir. Alt boyutlar noktasında puan ortalamaları dikkate alınarak bir değerlendirme yapıldığı takdirde, okul kültürü alt boyutlarına ilişkin en yüksek ortalama değerin amaç birliği alt boyutunda olduğu görülmektedir. Amaç birliği alt boyutunu sırasıyla mesleksel destek, mesleksel gelişim, işbirlikçi liderlik alt boyutları izlemektedir. En düşük ortalamanın ise öğretmen işbirliği alt boyutunda olduğu görülmektedir. Bu bulgular ise, Demirtaş'in (2010) elde ettiği bulgularla örtüşmektedir.

Kadın öğretmenlerin puan ortalamaları ile erkek öğretmenlerin puan ortalamaları arasında işbirlikçi liderlik boyutu dışında anlamlı bir farklılık görülmemiştir. İşbirlikçi liderlik boyutunda erkek öğretmenlerin lehine anlamlı bir farklılık olduğu görülmektedir. Dikkat çeken bir diğer nokta ise, tüm alt boyutlarda erkek öğretmenlerin puan ortalamalarının kadın öğretmenlerden daha yüksek olduğudur. Bu sonuç erkek öğretmenlerin okul kültürü algılarının kadın öğretmenlerin okul kültürü algılarından daha yüksek olduğu şeklinde açıklanabilir. Işık (2017), yaptığı çalışmada okul kültürünün hiçbir alt boyutunda cinsiyete göre istatistiksel açıdan herhangi bir fark olmadığı sonucuna ulaşmıştır. Bu bulgu araştırmamızın sonucu ile örtüşmemektedir.

Yaş değişkenine göre öğretmenlerin okul kültürü algıları arasında anlamlı bir farkın olmadığı görülmüştür. Bu bulgu Şahin (2017) ve Kolatan'ın (2008) elde ettikleri bulgular ile örtüşmektedir. Ancak mesleksel destek alt 
boyutu hariç, diğer alt grupların tamamında 41 ve üzeri yaşa sahip olan öğretmenlerin puan ortalamalarının, diğer gruplardaki öğretmenlerin puan ortalamalarından yüksek olduğu görülmektedir. Mesleksel destek alt boyutunda ise, 31-40 arası yaşa sahip olan öğretmenlerin puan ortalamaları, diğer gruplardaki öğretmenlerin ortalamalarından yüksektir. Bu sonuç 31-40 arası yaşa sahip olan öğretmenlerin okul kültürü algılarının diğer gruplardaki öğretmenlerin okul kültürü algılarından daha yüksek olduğu şeklinde açıklanabilir

Öğretmenlikteki hizmet süresi değişkenine göre öğretmenlerin okul kültürü algılarında mesleksel gelişim, amaç birliği ve mesleksel destek alt boyutlarında anlamlı farklar olduğu görülmüştür. 6-15 yıl hizmet süresine sahip öğretmenlerin mesleki gelişim, amaç birliği ve mesleksel destek algılarının 16-25 yıl hizmet süresine sahip öğretmenlerden daha yüksek olduğu sonucuna ulaşılmıştır. Ayrıca dikkat çeken bulgulardan biri de 25 yıl ve üzeri kıdeme sahip öğretmenlerin puan ortalamalarının, öğretmen işbirliği alt boyutu hariç diğer tüm alt boyutlarda diğer gruplardaki öğretmenlerin puan ortalamalarından yüksek olduğudur. Öğretmen işbirliği alt boyutunda ise, 6-15 yıl kıdeme sahip öğretmenlerin puan ortalamaları diğer grupların puan ortalamalarından yüksektir. Şahin (2017) ve Kolatan (2008) yaptıkları çalışmada kıdem değişkenine göre öğretmenlerin okul kültürü algılarında herhangi bir fark olmadığı sonucuna ulaşmışlardır. Bu bulgu araştırmamız sonuçlarıyla örtüşmemektedir. Güngör (2019) ise yaptığ 1 çalışmada okul kültürünün tüm alt boyutlarında kıdeme göre anlamlı farklar olduğu sonucuna ulaşmıştır. Kıdemi 21 yıl ve üstü olan öğretmenlerin okul kültürü algılarının 6-10 yıl arası kıdeme sahip olan öğretmenlerin okul kültürü alg1larından yüksek olduğu sonucuna ulaşmıştır.

Çalışlan okuldaki hizmet süresi değişkenine göre öğretmenlerin okul kültürü algılarının benzer olduğu, aralarında anlamlı bir farkın olmadığı sonucuna ulaşılmıştır. Bu bulguya göre çalıştıkları okullarda farklı hizmet süresine sahip olan öğretmenler, okul kültürü hakkında benzer görüşlere sahiptirler. Bu sonuç Taner (2008) ve Yıldırım'ın (2019) elde ettiği bulgularla örtüşmektedir. Işık (2017) ise yaptığı çalışmada öğretmenlerin çalıştıkları okuldaki hizmet süresi değişkenine göre başarı kültürü alt boyutunda anlamlı bir ilişki olduğu sonucuna ulaşmıştır. Aynı okulda 5 yıl ve daha az çalışan öğretmenlerin başarı kültürü algıları, 10 yıl ve daha fazla çalışan 
öğretmenlerden daha yüksek çıkmıştır. Bu bulgu araştırmamız sonucu ile örtüşmemektedir.

Okul kültürü ölçeğinin tüm alt boyutlarında herhangi bir sendikaya üye olan öğretmenlerin puan ortalamaları ile herhangi bir sendikaya üye olmayan öğretmenlerin puan ortalamaları arasında anlamlı bir farklılık görülmemiştir. Aynı zamanda öğretmen işbirliği alt boyutu dışında tüm alt boyutlarda sendikaya üye olan öğretmenlerin puan ortalamalarının, sendika üyesi olmayan öğretmenlerin puan ortalamalarından yüksek olduğu görülmektedir. Bu durum herhangi bir sendikaya üye olan öğretmenlerin işbirlikçi liderlik, mesleksel gelişim, amaç birliği ve mesleksel destek algılarının sendika üyesi olmayan öğretmenlerden daha yüksek olduğu şeklinde yorumlanabilir. Aktaş (2019), yaptığ çalışmada destek alt boyutu dışında tüm alt boyutlarda sendika üyesi olan öğretmenlerin okul kültürü algılar1nın sendika üyesi olmayan öğretmenlerin okul kültürü algılarından daha yüksek çıktığı sonucuna ulaşmıştır. Bu bulgu araştırmamız sonuçlarıyla benzerlik göstermektedir.

- Okulların daha kaliteli yönetilebilmesi, yöneticilerin daha donanıml olabilmesi, okullarda güçlü ve olumlu bir okul kültürünün oluşturulabilmesi için yönetici atamalarında eğitim yönetiminden veya eğitim ile ilgili herhangi bir alandan yüksek lisans yapma şartı getirilebilir.

- Okul kültürü okuldaki tüm paydaşların ortak ürünüdür. Bu nedenle Milli Eğitim Bakanlığı ile İl ve İlçe Milli Eğitim Müdürlüklerinin okullarda olumlu bir okul kültürünün oluşturulması için öğretmen, idareci ve diğer çalışanları hizmet içi eğitime alması önerilebilir.

- Okul kültürünün tüm alt boyutlarında erkek öğretmenlerin puan ortalamalarının kadın öğretmenlerin puan ortalamalarından yüksek çıkması nedeniyle, kadın öğretmenlerin okul kültürü algılarının hangi seviyede olduğu veya neden erkek öğretmenlere göre düşük olduğu konusunda daha kapsamlı bir çalışma yapılabilir.

- $\mathrm{Bu}$ araştırmanın evrenini Malatya il merkezi ve ilçelerindeki anaokullarında görev yapan öğretmenler oluşturmaktadır. Literatür incelendiğinde bu tür çalışmaların anaokulları düzeyinde nerdeyse hiç yapılmadığı görülmektedir. Böyle bir çalışmanın farklı illerde anaokullarında ve anasınıflarında çalışan öğretmenlerin okul kültürü algılarını ortaya koymak için yapılması önerilir. 


\title{
EXTENDED ABSTRACT
}

\section{School Culture Perceptions of Teachers Working in Kindergartens}

\author{
* \\ Nejla Bayer Demirhan - Zülfü Demirtaş \\ Firat Üniversitesi
}

As every society has its own culture, the schools established to raise qualified people also have their own culture. Some schools have a culture that differentiates them from other schools, informs new participants about the school, creates a sense of unity and solidarity in the school, contributes to the achievement of the school's ultimate goal and is effective in its success. The concept of culture, knowledge and education; civilization and civilization; It is used for fine arts and production (Şişman, 1994, p.41). It is seen that schools operate in the education-teaching process by taking inputs from their environment in order to achieve the goals of the society they are in, and transfer all kinds of values to students (Balc1, 2005, p. 161). Thus, the existing culture of the school is presented to the society in the form of output.

In schools that have a strong culture and are well managed, teachers enjoy their duties, students enjoy being at school, the school becomes an attraction for the outside environment, and students' academic success increases. In such a school environment, organizational commitment increases and all stakeholders of the school are proud of their schools. This situation creates a positive effect on the continuity and power of the school culture (Önsal, 2012, p. 35).

School culture; teachers own the school, do their jobs lovingly, make positive contributions to students' academic and social success, and work in collaboration with their colleagues. A school with a strong culture is expected to be more effective in achieving educational goals than a school with a poor culture. We can say that the most effective way to understand whether the dominant culture in schools is strong or weak is through measuring teachers' perceptions. The main purpose of this study is to reveal the school culture perceptions of teachers working in kindergartens. 
The study is a screening-type study to determine the perceptions of teachers working in kindergartens about school culture and whether these perceptions differ according to the variables of gender, age, seniority, length of service at school and union membership.

The universe of the study consists of teachers working in kindergartens in the 2019-2020 academic year, affiliated to Malatya provincial and district national education directorates. Within the scope of the study, all kindergartens in Malatya city center and its districts were reached. Scales were distributed to all 248 teachers working in 42 kindergartens, but 3 questionnaires that were found to be not filled in properly were excluded from the 187 returned questionnaires. Teachers participating in the research constitute $75 \%$ of the research universe.

The data collection tool consists of two parts. The first part includes demographic information consisting of a total of five variables including the teachers' gender, age, length of service in teaching, length of service at the school they work, and union membership status. In the second part, there is the "School Culture Scale" developed by Demirtaş (2010a), which consists of 27 items. When the histogram and Q-Q plot graphics of the school culture scale are examined, it is seen that the scale total scores show a normal distribution.

When an evaluation is made by considering the mean scores of the school culture scale in all sub-dimensions, it is seen that teachers' perceptions of school culture are at the top level. If an evaluation is made by considering the mean scores at the point of sub-dimensions, it is seen that the highest average value for the sub-dimensions of school culture is in the unity of purpose sub-dimension. Professional support, professional development, collaborative leadership sub-dimensions follow the sub-dimension of unity of purpose, respectively. It is seen that the lowest average is in the teacher cooperation sub-dimension.

Except for the collaborative leadership dimension, there was no significant difference between the mean scores of female teachers and male teachers. It has been observed that there is no significant difference between teachers' perceptions of school culture according to the age variable. However, except for the vocational support sub-dimension, it is seen that the mean scores of the teachers who are 41 and above in all other subgroups are higher than the mean scores of the teachers in the other groups. 
In the vocational support sub-dimension, the mean scores of teachers between the ages of 31-40 are higher than the average of teachers in other groups. This result can be explained as that teachers who are between 31-40 years old have higher perceptions of school culture than teachers in other groups.

According to the variable of service time in teaching, there are significant differences in teachers' perceptions of school culture in the sub-dimensions of professional development, unity of purpose and professional support. It was concluded that the perceptions of professional development, unity of purpose and professional support of teachers with a service period of 6-15 years were higher than teachers with a service period of 16-25 years. In addition, one of the striking findings is that the mean scores of teachers with seniority of 25 years or more are higher than the average scores of teachers in other groups in all sub-dimensions except for teacher collaboration.

It was concluded that teachers' perceptions of school culture were similar, and there was no significant difference between them, according to the variable of service time at the school where they worked. In all subdimensions of the school culture scale, there was no significant difference between the mean scores of teachers who are members of a union and the mean scores of teachers who are not members of any union. At the same time, it is seen that the mean scores of the teachers who are members of the union are higher than the mean scores of the teachers who are not union members in all sub-dimensions except the teacher cooperation subdimension.

\section{Kaynakça / References}

Akkaşoğlu, N. H. (2015). Ortaöğretim okullarnndaki öğretmenlerin örgüt kültürüne ilişkin görüşleri ve yönetime katılma düzeyleri. Yayımlanmamış yüksek lisans tezi. Okan Üniversitesi, Sosyal Bilimler Enstitüsü, İstanbul.

Aktaş, E. (2019). İlkokul öğretmenlerinin okul kültürü algz düzeylerinin incelenmesi. Yayımlanmamış yüksek lisans tezi. İstanbul Sabahattin Zaim Üniversitesi, Sosyal Bilimler Enstitüsü, İstanbul.

Atay, K. (2001). Öğretmen, yönetici ve denetmenlerin bakış açısından okul kültürü ve ögretmen verimliliğine etkisi. Kuram ve Uygulamada Ĕ̆itim Yönetimi. 179194. 
Balcı, A. (2005). Açıllamalı eğitim yönetimi terimleri sözlü̈̆̈̈ (1. Baskı). Ankara: Tek Ağaç Basım.

Balc1, A. (2007). Etkili okul ve okul geliştirme (4. Baskı). Ankara: Pegema Yayıncllk.

Celep, C. (2002). İköğretim okullarında öğrenme kültürü. Kuram ve Uygulamada Eğitim Yönetimi, 8, 356-373.

Çelik, V. (2002). Okul külttürü ve yönetimi (3. Baskı). Ankara: Pegem A Yayıncllk.

Çelik, V. (2005). Sinıf yönetimi (7. Baskı). Ankara: Nobel Yayın Dağıtım.

Çelikten, M. (2006). Okul kültürünün şekillendirilmesinde müdürün rolleri. Eğitim ve Bilim, 31 (140), 56-61.

Demirtaş, Z. ve Ekmekyapar, M. (2012). İköğretim okulu yöneticilerinin değerlere dayalı yönetim uygulamalarının okul kültürüne etkisi . Kuram ve Uygulamada Ĕ̈itim Yönetimi Dergisi, 18 (4), 523-544.

Demirtaş, Z. (2010a). Okul kültürü ile öğrenci başarısı arasındaki ilişki / The relationship between school culture and student achievement. Eğitim ve Bilim / Education and Science, 35 (158), 3-13.

Demirtaş, Z. (2010b), Liselerde okul kültürü ile öğrenci başarısı arasındaki ilişki. Mustafa Kemal Üniversitesi Sosyal Bilimler Enstitüsü Dergisi, 7 (13), 208-223

Frrat, N. (2007). Okul kültürü ve öğretmenlerin değer sistemleri. Yayımlanmamış doktora tezi. Dokuz Eylül Üniversitesi, Eğitim Bilimleri Enstitüsü, İzmir.

Furat, Ş. N. (2010). Okul müdürü ve öğretmenlerin okul kültürü ile değerler sistemlerine ilişkin algiları. Eğitim ve Bilim Dergisi, 35(156), 71-83.

Fichter, J. (2002). Sosyoloji nedir?. (Çev. N. Çelebi). Ankara: Anı Yayıncllk.

Güngör, B. (2019). Öğretmenlerin örgütsel sessizlik algilar ile okul kültürü algilarn arasındaki ilişki. Yayımlanmamış yüksek lisans tezi. On dokuz Mayıs Üniversitesi, Eğitim Bilimleri Enstitüsü, Samsun.

Işık, H. (2017). Ortaokullarda okul kültürünün incelenmesi. Yayımlanmamış yüksek lisans tezi. Yıldız Teknik Üniversitesi ve İstanbul Aydın Üniversitesi, Sosyal Bilimler Enstitüsü, İstanbul.

Jerald, C. D. (2006). School culture: the hidden curriculum. For Comprehensive School Reform and Improvement. 1-7.

Kolatan, R. (2008). Eğitim yöneticilerinin okul kültürünün oluşturulmasinda ve sürdürülmesindeki rolü. Yayımlanmamış yüksek lisans tezi. Yeditepe Üniversitesi, Sosyal Bilimler Enstitüsü, İstanbul.

Köse, Ö., Kalyoncu, M., Karataş, K., Erol, A. E., Usta, E., Demiralp, O., . . , Karaman, U. (2010). Hoşgeldin öğretmenim. Ankara: MEB. 25-26.

Kuyumcu, M. (2007). İlköğretim okullarnnda okul kültürü ve takım liderliği. Yayımlanmamış doktora tezi. Fırat Üniversitesi, Sosyal Bilimler Enstitüsü, Elazığ. 
Önsal, A. (2012). Okul müdürlerinin iletişim becerileri ile okul kültürü arasindaki ilişki. Yayımlanmamış yüksek lisans tezi. Maltepe Üniversitesi, Sosyal Bilimler Enstitüsü, İstanbul.

Recepoğlu, E. (2014). Okul külttüründe liderlik. N.Güçlü (Ed.). Okul Kültürü içinde (s. 205-240). Ankara, Pegem Akademi Yayınları,

Şahin, M. (2017). Öğretmenlerin yetkinlik alg̨lar ile okul kültürü algıları arasındaki ilişkinin incelenmesi. Yayımlanmamış yüksek lisans tezi. Marmara Üniversitesi, Sosyal Bilimler Enstitüsü, İstanbul.

Şişman, M. (1994). Örgüt kültürü: Eskişehir il merkezindeki okullarda bir araştırma. Eskişehir, Anadolu Üni. Yayınları.

Taner, D. (2008). Ö̆gretmenlerin umutsuzluk düzeyi ile okul kültürü arasındaki ilişki. Yayımlanmamış yüksek lisans tezi. Yeditepe Üniversitesi, Sosyal Bilimler Enstitüsü, İstanbul.

Turhan, M. (2007). Genel ve mesleki lise yöneticilerinin etik liderlik davranışlarmın okullardaki sosyal adalet üzerindeki etkisi. Yayımlanmamış doktora tezi. Furat Üniversitesi, Sosyal Bilimler Enstitüsü, Elazı̆g.

Yıldırım, E. (2019). Ortaöğretim öğretmenlerinin örgütsel adanmışlı̆̆ ile okul kültürü arasındaki ilişki. Yayımlanmamış yüksek lisans tezi. Yıldız Teknik Üniversitesi, Sosyal Bilimler Enstitüsü, İstanbul.

\section{Kaynakça Bilgisi / Citation Information}

Bayer Demirhan, N. ve Demirtaş, Z. (2021). Anaokullarında görev yapan öğretmenlerin okul kültürü algıları. OPUS-Uluslararası Toplum Araştırmaları Dergisi, 17(35), 1729-1754. DOI: 10.26466/opus.778544 